\title{
Reverse latissimus dorsi muscle flap for complex back defects: our experience
}

\author{
Kumaraswamy Mohan Kumar, Shantha Kumar Shivalingappa, Veena Prabhakar Waiker, Udaya Shankar Odeyar \\ Department of Plastic Surgery, M.S. Ramaiah Medical College, Bangalore 560054, India.
}

Correspondence to: Dr. Kumaraswamy Mohan Kumar, Department of Plastic Surgery, M.S. Ramaiah Medical College, New bel Road, Bangalore 560054, India. E-mail: doctorkums@rediffmail.com

How to cite this article: Kumar KM, Shivalingappa SK, Waiker VP, Odeyar US. Reverse latissimus dorsi muscle flap for complex back defects: our experience. Plast Aesthet Res 2017;4:76-81.

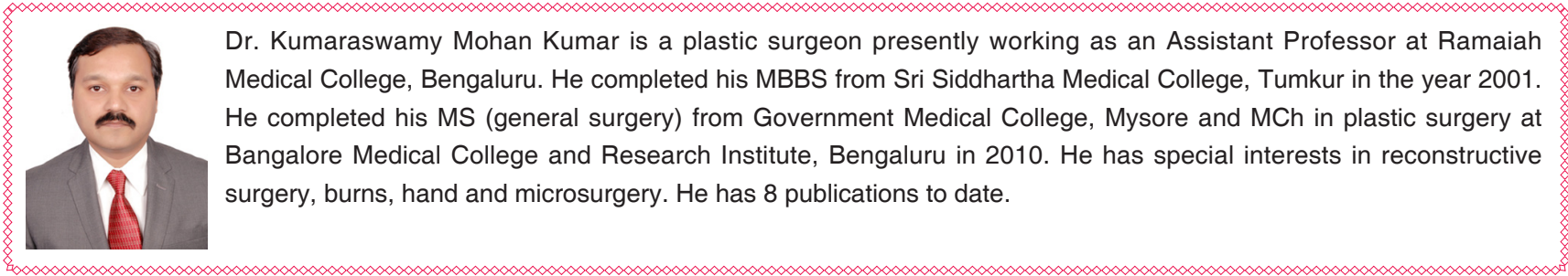

Article history:

Received: 24-02-2017

Accepted: 18-04-2017

Published: 26-05-2017

\section{Key words:}

Reverse latissimus dorsi muscle flap, complex back defects, reverse turn over flap

\section{ABSTRACT}

Aim: The aim was to study the effectiveness of the reverse latissimus dorsi muscle flap in reconstruction of complex defects of the back. Methods: This is a retrospective study of patients who underwent reverse latissimus dorsi flap for reconstruction of the back, in a tertiary care hospital. The patient demographics, etiology, surgery indications and complications were studied. Results: The study had five patients between 2012 and 2016 who underwent reverse latissimus dorsi flap for reconstruction. The flaps survived in all the patients. Two patients had complications, unrelated to the latissimus dorsi muscle flap. Conclusion: The vascularity of the flap is reliable can be used to obliterate the dead space, can be used to control the infection, in complex cases of the back.

\section{INTRODUCTION}

The back has the vertebrae in the middle and exposure of the bone gives us a complex defect. The etiology includes myelomeningocele defects, post excision defects of the back, and pressure sores. The various options for coverage of myelomeningocele defects include local skin flaps, skin graft, latissimus dorsi muscle flap and othervariations. ${ }^{[1]}$ The latissimus dorsi flap is a versatile flap based on the thoracodorsal vessels and the perforators from the posterior intercostal and lumbar perforators. It is a type $\mathrm{V}$ muscle flap based on the Mathes and Nahai classification. ${ }^{[2]}$ The latissimus dorsi muscle is frequently used based on the thoracodorsal pedicle. The reverse latissimus dorsi flap is based on the secondary pedicles which are the perforators from the posterior intercostal and lumbar vessels. ${ }^{[2]}$ The reverse latissimus dorsi flap is used for coverage of the midline

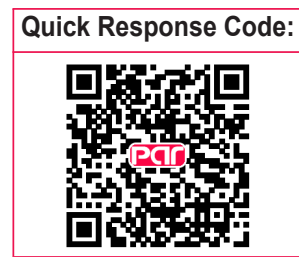




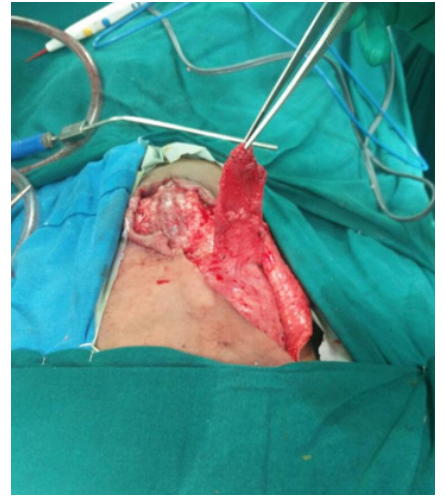

Figure 1: Latissimus dorsi muscle flap raised based on the secondary pedicle

and contralateral back, lumbar and sacral midline. This muscle flap can also be used for the reconstruction of the diaphragm. ${ }^{[3]}$ Simple midline defects can be covered by various fasciocutaneous flaps like rhomboid, transposition, rotation, advancement, Z flaps, S flaps, lumbar perforator based flaps, etc. ${ }^{[2]}$ Complex defects in the lower back over the lumbar and sacral region are a difficult problem for plastic surgeons. In complicated cases, we cannot rely on these fasciocutaneous flaps alone, we need to combine muscle flaps with either fasciocutaneous flaps or skin grafts. Muscle flaps have many advantages: they are sturdy, more vascular, have alarge surface area that can be used to obliterate dead space. For coverage of complex posterior defects, we can use gluteus maxims, latissimus dorsi muscle flaps alone or with other variations.

The gluteus maximus muscle can be used to cover sacral defects. However, lumbar defects are not as easy covered. The ipsilateral latissimus dorsi flap based on the thoracodorsal vessels can be moved medially to cover the lumbar region. The turnover of the latissimus dorsi flap from lateral to medial side can be used to cover the midline thoracic defects. These flaps are based on the thoracodorsal vessels. Latissimus dorsi musculocutaneous flaps with the skin extending to the posterior axillary line would cover the lower lumbar and sacral defects.

\section{METHODS}

A retrospective study was conducted in a tertiary care hospital of patients who underwent reverse latissimus dorsi flaps between February 2012 and December 2016.

There are 5 cases in this study. The patient records were analyzed for the age, gender, indications, surgical procedure, defect size, complications. The neurosurgeons released the tethered spinal cords in case of myelomeningocele in first 3 cases, excised the

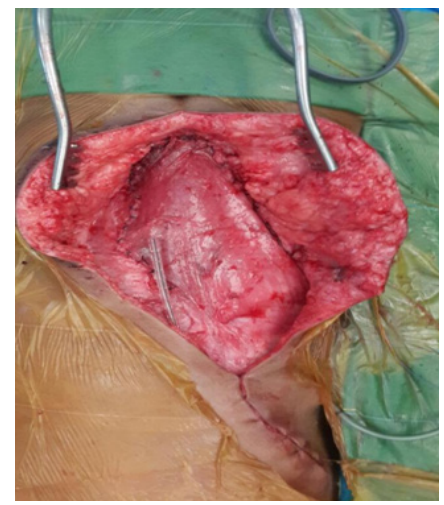

Figure 2: Latissimus dorsi muscle inset given, donor site closed. Viability confirmed before closing the wound

recurrent sacral cordoma in the fourth case, while the onco surgeons excised the sarcoma of the chest wall in the fourth case. After the primary surgeries as mentioned above, the cases were presented for reconstruction. The dura was reinforced with sutures and fibrin in cases with myelomeningocele. An oblique incision from the edge of the defect to the ipsilateral axilla was used to expose the latissimus dorsi muscle. The skin flaps were raised. The muscle was cut at $10 \mathrm{~cm}$ from the insertion. The thoracodorsal vessels and nerve were identified, ligated and divided. The muscle was raised from the undersurface until the secondary pedicles were identified [Figure 1]. The muscle was turned over to the defect in such a way that superficial surface of the muscle covered the defect. After turnover, the flap was inset with absorbable sutures. Flap vascularity was confirmed by color and distal tip bleeding [Figure 2]. Over this muscle flap, adjacent fasciocutaneous flaps were advanced. The donor site was closed in layers and a drain was placed. Post operatively patients were nursed in either prone or lateral position. Sutures were removed by 15 days and the drain by 10 days.

\section{Case 1}

This patient had a myelomeningocele with raised intracranial pressure and a ventriculoperitoneal shunt. We had high suspicion that there might be a cerebrospinal fluid leak (CSF leak) [Figure 3]. Hence, a muscle flap was planned to cover the defect including any minor leaks and to provide a vascular cover over the dura. A reverse latissimus dorsi muscle flap was used to cover the defect and a fasciocutaneous flap was advanced over the muscle [Figure 2]. The postoperative course was complicated by $1 \mathrm{~cm}$ skin necrosis, which was dressed regularly and allowed to heal by secondary intention.

\section{Case 3}

This patient was operated for amyelomeningocele of the lumbosacral region. The tethered cords were released and dura was repaired by the neurosurgeons. 


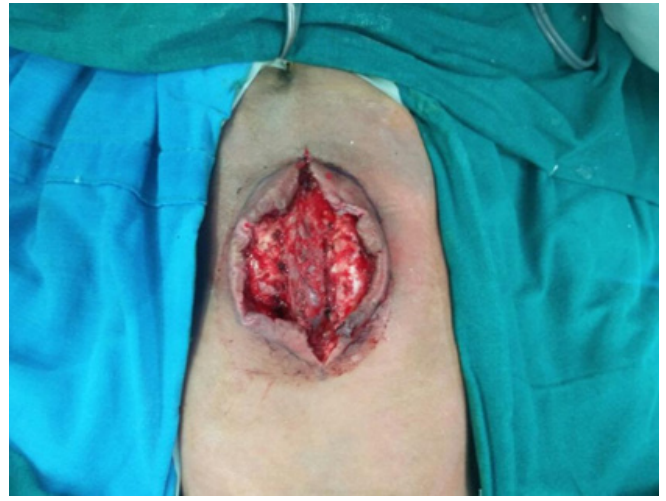

Figure 3: Case 1. Myelomeneingocle defect, after release of teethered cords

The skin adjacent to the defect was advanced to close the defect. She developed CSF leak manifesting as swelling in the operated site and also excess drainage collection. She was reexplored to correct the CSF leak. The dura was reinforced with sutures and glue. The reverse latissimus dorsi turnover flaps were used to cover this complicated myelomeningocele defect. Here, the distal end of the latissimus dorsi flap was not showing adequate vascularity and was debrided. This flap was able to cover only the upper two thirds of the defect. A contralateral gluteus maximus muscle flap was advanced to the lower part of the defect [Figure 4]. The skin was advanced to cover the defect. The wound healed well with no complications.

\section{RESULTS}

A total of 5 patients [Table 1] were treated with a reverse latissimus dorsi flap for various defects of the back. Among these 5 patients, 2 were male and 3 were female. Three patients aged below 2 years and 2 patients aged 55 years and 60 years. Two patients had

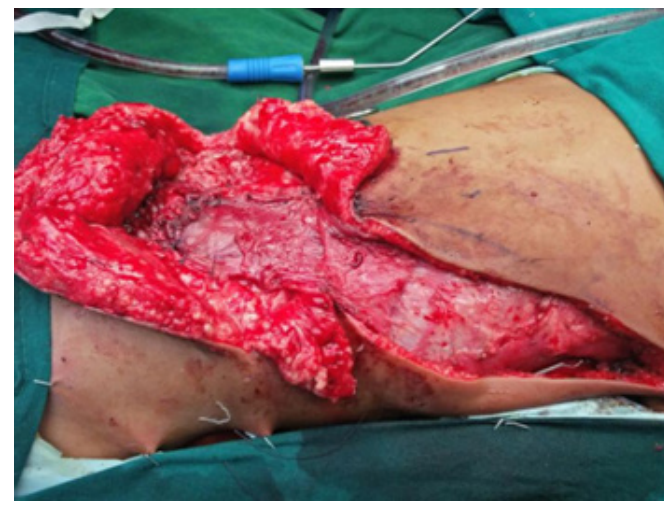

Figure 4: Case 3. Reverse latissimus dorsi muscle flap and gluteus muscle flap to cover the myelomeningocele defect

cancer excision and 3 patients had myelomeningocele correction. Four patients underwent turnover of the reverse latissimus dorsi flap and 1 patient had transposition of the reverse latissimus dorsi flap. All 4 reverse latissimus dorsi turnover muscle flap were done by a single surgeon and the reverse latissimus dorsi muscle transposition flap was done by another surgeon. Four patients had advancement of fasciocutaneous flaps over the muscle flap; 1 patient had a split thickness skin graft over the muscle.

The indications for the use of a muscle flap in these cases were CSF leak, sinus, wound dehiscence, need for vascular cover over the implants, obliteration of the dead space, and to reconstruct the chest wall defect.

Two patients had prior surgery within a week before the reverse latissimus dorsi flap was used to cover the defect. Three patients had not undergone prior surgery.

In case 3, the distal muscle did not look healthy; hence the contralateral gluteus maximus flap was raised

Table 1: All the cases included in the study

\begin{tabular}{|c|c|c|c|c|c|c|}
\hline No. & $\begin{array}{l}\text { Age/ } \\
\text { gender }\end{array}$ & Diagnosis & Indication & Defect size & $\begin{array}{l}\text { Muscle flap used and } \\
\text { movement of flap }\end{array}$ & $\begin{array}{l}\text { Complications after } \\
\text { the surgery }\end{array}$ \\
\hline 1 & $\begin{array}{l}9 \text { days } / \\
\text { male }\end{array}$ & $\begin{array}{c}\text { Lumbosacral } \\
\text { myelomeningocele }\end{array}$ & $\begin{array}{l}\text { Associated with hydrocephalus, } \\
\text { had a ventriculo-peritoneal shunt, } \\
\text { high suspicion of chance of CSF } \\
\text { leak from the dural patch }\end{array}$ & $\begin{array}{c}10 \mathrm{~cm} \times 8 \mathrm{~cm} \\
\text { lumbosacral } \\
\text { defect }\end{array}$ & RLDMF turnover & $\begin{array}{l}\text { Skin edge necrosis } \\
\text { of } 1 \mathrm{~cm} \text {, was allowed } \\
\text { to heal by secondary } \\
\text { intention }\end{array}$ \\
\hline 2 & $\begin{array}{l}14 \\
\text { months/ } \\
\text { male }\end{array}$ & $\begin{array}{l}\text { Lumbosacral } \\
\text { myelomeningocele }\end{array}$ & $\begin{array}{c}\text { Operated } 4 \text { days before, developed } \\
\text { CSF leak }\end{array}$ & $\begin{array}{l}12 \mathrm{~cm} \times 5 \mathrm{~cm} \\
\text { lumbosacral } \\
\text { defect }\end{array}$ & RLDMF turnover & Nil \\
\hline 3 & $\begin{array}{c}12 \\
\text { months/ } \\
\text { female }\end{array}$ & $\begin{array}{l}\text { Lumbosacral } \\
\text { myelomeningocele }\end{array}$ & $\begin{array}{l}\text { Operated } 1 \text { week before and } \\
\text { developed CSF leak }\end{array}$ & $\begin{array}{c}14 \mathrm{~cm} \times 6 \mathrm{~cm} \\
\text { lumbosacral } \\
\text { defect }\end{array}$ & $\begin{array}{l}\text { RLDMF turnover and } \\
\text { GMMF }\end{array}$ & Nil \\
\hline 4 & $\begin{array}{l}55 \text { years/ } \\
\text { female }\end{array}$ & $\begin{array}{l}\text { Recurrent sacral } \\
\text { chordoma of sacral } \\
\text { and lumbar vertebrae }\end{array}$ & $\begin{array}{l}\text { Cross linking of left and right iliac } \\
\text { bones with the lumbar bones using } \\
\text { pedicle screws after sacrectomy }\end{array}$ & $\begin{array}{l}15 \mathrm{~cm} \times 20 \mathrm{~cm} \\
\text { lumbosacral } \\
\text { defect }\end{array}$ & $\begin{array}{l}\text { RLDMF turnover and } \\
\text { FCRF }\end{array}$ & Nil \\
\hline 5 & $\begin{array}{l}61 \text { years/ } \\
\text { female }\end{array}$ & $\begin{array}{l}\text { Spindle cell tumor } \\
\text { of lung and lower } \\
\text { posterior chest wall }\end{array}$ & $\begin{array}{l}\text { Excision included posterior chest } \\
\text { wall and lower lobe of lung }\end{array}$ & $\begin{array}{l}12 \mathrm{~cm} \times 10 \mathrm{~cm} \\
\text { thoracic defect }\end{array}$ & RLDMF transposition & $\begin{array}{l}\text { Excision margins were } \\
\text { positive for malignancy } \\
\text { and patient declined } \\
\text { further intervention }\end{array}$ \\
\hline
\end{tabular}

CSF: cerebrospinal fluid; RLDMF: reverse latissimus dorsi muscle flap; GMMF: gluteus maximus muscle flap; FCRF: fasciocuatneous rotation flap 
and advanced to cover the lower defect. At the end of surgery, both muscles were healthy. We identified three big lower perforators, but even then the vascularity of the muscle tip was inadequate.

In case 5 the flap dehisced, there were increased secretions from the wound, empyema due to incomplete excision of the tumor and patient was unwilling to undergo further procedures. The flap in case 5 looked healthy and the skin graft take was more than $90 \%$.

Otherwise, the other 4 cases had no postoperative fevers, increase in discharge or particulate matter in the drain, which suggested a healthy muscle flap.

There were no donor site complications in any of the above cases. All these patients, except for case 5 , followed up for six months and had no problems recorded with regards to shoulder movement.

\section{DISCUSSION}

The most common indication for the use of the reverse latissimus dorsi muscle flap has been a complex defect or a complicated defect, like infected ulcer, post radiotherapy ulcer, CSF leaks. ${ }^{[4-8]}$ In the present study we have used it for complex wounds with CSF leak, prosthesis in situ. The reverse latissimus dorsi is considered only as an alternative for meningomyelocele closure. Ayad et al. ${ }^{[4]}$ used the reverse latissimus dorsi flap as a primary reconstruction for large defects.

The reverse latissimus dorsi muscle flaps are based on the perforators from the posterior intercostal vessels and the lumbar vessels. The turnover of the reverse latissimus dorsi muscle flap from upper back to the lower back can cover midline lumbar and sacral defects. The reverse latissimus dorsi muscle flap can be transposed to cover the lumbar orthoracic defects and can be used inside the chest. The superior perforators can be divided for adequate reach of the flap, but the inferior pedicles need to be preserved for the survival of the flap. In case 3 the distal part of the latissimus dorsi flap was not healthy and thus we had to debride part of the flap. We felt the secondary pedicles were not sufficient to vacularise the distal end. Studies have found that the vascularity of the reverse latissimusdorsi flap is reliable. ${ }^{[4,5]}$

There is thinning of the skin over the myelomeningocele. There is decreased soft tissue support in the midline if the skin over the defect is thinned by expansion. The use of a muscle cover in addition to the fasciocutaneous flap, over the repaired dura will give additional support as well as act as a vascularized cover over the dura.
The layered closure had helped Söyüncü et al. ${ }^{\left[{ }^{9]}\right.}$ to decrease the CSF leakage by using omentum and latissimus dorsi flap.

A reverse latissimus dorsi flap can also be usedfor 3D coverage and to control bacterial contamination. ${ }^{[5,6,10]}$ In our experience, complicated acquired defects (like in the fourth case) require muscle to fill the dead space around the fixators as a first layer to cover the implants. Dead space is a potential space for seroma collection and infection. So, with amuscle flap we were able to successfully prevent the formation of seroma and infection.

Large meningomyelocele defects have also been reconstructed with reverse latissimus dorsi flap and skin graft. ${ }^{[7]}$ In one case we decided to leave the wound to heal by secondary intention as the skin necrosis defect was $1 \mathrm{~cm}$ in size. We had a healthy muscle covering the dura and hence, we were able to allow for secondary intention without the risk of dura break down and infection.

Latissimus dorsi muscle is a type $\mathrm{V}$ muscle flap based on thoracodorsal artery and perforators from the lumbar and posterior intercostal vessels. These perforators are usually present $5 \mathrm{~cm}$ from the midline. ${ }^{[11]}$ The perforators were present within $5 \mathrm{~cm}$ of the midline in our series. All the flaps except 1 survived without any distal necrosis, even though the distal perforators were intact. The distal 2 perforators are enough for the survival of the muscle for the lower part of the muscle. ${ }^{[12]}$ Hayashida et al. ${ }^{[13]}$ have published a case report on reverse latissimus dorsi flap based on the tenth perforator. In the above case the reach of the flap was up to the anterior superior iliac spine. In our cases the flaps reached the lower sacrum without tension or compromise on the muscle vascularity in all cases except 1 case. Though, many authors have described that the flap can survive with the lower 9th and 10th perforators ${ }^{[13]}$ we feel distal flap necrosis may be encountered. We do not have a large series as proof, hence further studies would be needed.

The flap reaches down to the lower sacrum, however, one might have difficulty covering the lower part of the sacrum. As an option, the gluteus maximus muscle flap can also be used as described in one of our cases. The most frequent complication of the latissimus dorsi muscle flap is seroma. ${ }^{[14]}$ However, in our serieswe did not encounter it.

The reverse latissimus dorsi flap is robust with a reliable vascularity. The chances of failure are small. Alternatives include the use of local flaps, which do 
not have the mopping qualities of the muscle. We can deepithelialise the skin flaps and use it to obliterate the dead space. This may lead to the development of epithelial cysts. Söyüncü et al. ${ }^{[9]}$ have used latissimus dorsi muscle flap along with omentum with a view that layered closure would decrease chances of CSF leak in recurrent cases of CSF leak.

Free flaps are an option, however the recipient vessels are deep and hard to find. The vessels which could be harvested as recipient are the superior gluteal vessels, inferior gluteal vessels, and intercostal vessels, perforators from the deep femoral system, ${ }^{[15]}$ superficial femoral trunk, and thoracodorsal vessels. The other possible methods of obtaining a recipient are using an interposition vein graft between the distant vessels to the donor vessels, ${ }^{[16]}$ or a carrier vessel may be used and flap transferred in stages. Reverse latissimus dorsi flap has been transferred to the defect and supercharged the flap by anastomosing the thoracodorsal vessels with the inferior gluteal vessels. ${ }^{[17]}$

We have followed up the patients for 6 months; the functional deficit of the shoulder could not be assessed in children. However there was no appreciable difference in movement of the shoulder when compared to the opposite shoulder. In case 4, we did not find any restriction when compared to the opposite shoulder. Case 5 was lost in follow up. Other studies regarding functional assessment have also found no significant shoulder function disability. ${ }^{[18,19]}$

Our study had 5 cases; it is not a comparative study. Further studies may be required to compare other flaps with the reverse latissimus dorsi flap to establish that it is a better choice in complex defects of the back. However, most of the authors in the literature have agreed that reverse latissimus dorsi flap is a choice for reconstruction of the back with CSF leaks, difficult wounds with infection, radiation, etc.

In conclusion, we feel that reverse latissimus dorsi muscle flap is a robust flap with reach up to the lower part of sacrum. We recommend it as a definite choice for big complicated meningomyelocele defect or any posterior defect in the lumbar and sacral region. We feel that this flap may be considered as a primary choice for big myelomeningocele defect. This needs further studies.

\section{Authors' contributions}

Manuscript's preparation: K.M. Kumar, V.P. Waiker, U.S. Odeyar

Manuscript's review: K.M. Kumar, V.P. Waiker, U.S. Odeyar
Concept design: K.M. Kumar

Literature search: K.M. Kumar

Case material's provide: K.M. Kumar, S.K. Shivalingappa

\section{Financial support and sponsorship}

None.

\section{Conflicts of interest}

There are no conflicts of interest.

\section{Patient consent}

Obtained.

\section{Ethics approval}

Obtained.

\section{REFERENCES}

1. Shaw WW, Aston SJ, Zide BM. Reconstruction of the Trunk. In McCarthy JG. Plastic Surgery vol 6. The trunk and lower extremity. Philadelphia: W.B. Saunders Company; 1990. p. 3675-796.

2. Mathes SJ, Nahai F. Latissimus dorsiflap. In: Mathes SJ, Nahai F Reconstructive Surgery Principles, Anatomy and Technique. New York: Churchill Liningstone; 1997. p. 565-615.

3. Sydorak RM, Hoffman W, Lee H, Yingling CD, Longaker M, Chang J, Smith B, Harrison MR, Albanese CT. Reverse latissimus dorsi muscle flap for repair of congenital diaphragmatic hernia. $J$ Pediatr Surg 2003;38:296-300.

4. Ayad W, Zayed EF, Refaae AS, Taman EA, Elewa S. The versatility of reversed turn over latissimus dorsi muscle flap for reconstruction of meningomyelocele defects. Egypt J Plast Reconstr Surg 2012;36:339.

5. Rajput DU, Muniswamy SB. Reverse latissimus dorsi turnover muscle flap for coverage of secondary midline lumbar defect following spinal surgery. J Spinal Surg 2016;3:12-4.

6. Yoo CM, Kang DH, Hwang SH, Park KB. Reverse latissimus dorsi muscle flap for an extensive soft tissue defect accompanied by infectious spondylitis. J Korean Neuro Surg Soc 2012;52:423-6.

7. Zakaria Y, Hasan EA. Reversed turnover latissimus dorsi muscle flap for closure of myelomeningocele defects. J Plast Reconstr Aesthet Surg 2010;63:1513-8.

8. Kotti B, Jaidane O, Ben Hassouna J, Rahal K. The "reverse" latissimus dorsi flap for large lower lumbar defect. Case Rep Surg 2012;2012:964625.

9. Söyüncü Y, Bigat Z, Söyüncü İ, Özkan Ö. Omentum and reverse turnover latissimus dorsi musculocutaneous flap for the treatment of cerebrospinal fluid fistula. Acta Orthop Traumatol Turc 2015;49:5715 .

10. de Fontaine S, Gaede F, Berthe JV. The reverse turnover latissimus dorsi flap for clsure of midline lumbar defects. J Plast Reconstr Aesthet Surg 2008;61:917-24.

11. Stevenson TR, Rohrich RJ, Pollock RA, Dingman RO, Bostwick J 3rd. More experience with the "reverse" latissimus dorsi musculocutaneous flap: precise location of blood supply. Plast Reconstr Surg 1984;74:237-43.

12. Watanabe K, Kiyokawa K, Rikimaru H, Koga N, Yamaki K, Saga T. anatomical study of latissimus dorsi musculocutaneous flap vascular distribution. J Plast Reconstr Aesthet Surg 2010;63:1091-8.

13. Hayashida K, Endo Y, Kamebuchi K. Case report reconstruction of exposed ilium with reverse turnover latissimus dorsi muscle flap. 
Eplasty 2011;11:e17.

14. Schwabeggar A, Ninkovic M, Brenner E, Anderl H. Seroma as a common donor site morbidity after harvesting the latissimus dorsi flap: observations on cause and prevention. Ann Plast Surg 1997;38:594-7.

15. Hung SJ, Chen HC, Wei FC. Free flaps for reconstruction of the lower back and sacral area. Microsurgery 2000;20:72-6.

16. Nahai F, Hagerty R. One-stage microvascular transfer of a latissimus flap to the sacrum using vein grafts. Plast Reconstr Surg 1986;77:3125 .

17. Cigna E, Mardini S, Chen HC, Özkan Ö, Sassu P, Salgado CJ,
Lieu YT, Ponzo I, Ribuffo D, Scuderi N. An improved method of supercharged transposed latissimus dorsi flap with the skin paddle for the management of a complicated lumbosacral defect. Eur Rev Med Pharmacol Sci 2015;19:921-6.

18. Osinga R, Mazzone L, Meuli M, Meuli-Simmen C, von Campe A. Assessment of long term donor site morbidity after harvesting the latissimus dorsi flap for neonatal myelomeningocele repair. J Plast Reconstr Aesthet Surg 2014;67:1070-5.

19. Latiung JK, Peck F. Shoulder function following the loss of the latissimus dorsi muscle. Br J Plast Surg 1985;38:375-9. 